\title{
Therapeutic effect of adipose-derived mesenchymal stem cells (ASCs) on radiation-induced skin damage in rats
}

\author{
Bijan Khademi ${ }^{1,2}$, Sima Safari ${ }^{2}$, Mohammad Amin Mosleh-Shirazi ${ }^{3}$, Maral Mokhtari ${ }^{4}$, \\ Nooshafarin Chenari ${ }^{5}$, Mahboobeh Razmkhah ${ }^{5}$ \\ ${ }^{1}$ Research Center of Otolaryngology Head and Neck Surgery, ${ }^{2}$ Department of Otolaryngology, ${ }^{3}$ Department of Radiotherapy and Oncology, Medical \\ Imaging Research Center, ${ }^{4}$ Department of Pathology, ${ }^{5}$ Institute for Cancer Research, School of Medicine, Shiraz University of Medical Sciences, \\ Shiraz, Iran \\ Contributions: (I) Conception and design: M Razmkhah, B Khademi; (II) Administrative support: M Razmkhah, B Khademi; (III) Provision of study \\ materials or patients: M Razmkhah, MA Mosleh-Shirazi; (IV) Collection and assembly of data: M Razmkhah, MA Mosleh-Shirazi, S Safari, M \\ Mokhtari, N Chenari; (V) Data analysis and interpretation: M Razmkhah, S Safari; (VI) Manuscript writing: All authors; (VII) Final approval of \\ manuscript: All authors. \\ Correspondence to: Mahboobeh Razmkhah, PhD. Institute for Cancer Research, School of Medicine, Shiraz University of Medical Sciences, Shiraz, \\ Iran. Email: razmkhahm@sums.ac.ir; mrazmkhah2@gmail.com.
}

Background: Radiation-induced skin injury remains a serious concern, which may limit the duration and dose of radiation treatment. The concept that stem cell injection may reduce tissue injury or assist its recovery after radiation has been recently argued. Herein, we examined the effect of adipose-derived mesenchymal stem cells (ASCs) on radiation-induced skin damage in rats.

Methods: This study is an experimental case control study. ASCs were isolated from peri uterine fat tissue of the rats. Then the rats received a $30 \mathrm{~Gy}$ single dose radiation to their buttocks skin using gamma radiation. Next day stem cells were transplanted subcutaneously in 16 rats as the case group. A group of 16 rats was considered as control group with radiation but no transplantation of stem cells. Then rats were examined and observed by macroscopic analysis and phenotypic scores during 4 weeks of follow up.

Results: The wound size in control group was significantly higher than case group in the second, third and fourth weeks of evaluation $(\mathrm{P}<0.05)$. There was no significant difference in skin lesion severity, pathological factors, and the onset of recovery signs between two groups $(\mathrm{P}>0.05)$.

Conclusions: It seems that using ASCs alone has not profound effects on reducing radiation-induced cutaneous complications, while combination of these cells with growth factors may produce more promising results.

Keywords: Mesenchymal stem cells (MSCs); wound healing; radiation; cutaneous complications; regeneration

Received: 30 October 2019; Accepted: 23 June 2020; Published: 15 July 2020.

doi: $10.21037 /$ sci-2019-045

View this article at: http://dx.doi.org/10.21037/sci-2019-045

\section{Introduction}

Mesenchymal stem cells (MSCs) are adult tissue-derived multipotent stromal cells (1) which were first discovered in bone marrow (BM) by Friedenstein et al. (2). They were later detected from various adult tissues, including adipose tissue, umbilical cord blood, placenta, liver, pancreas, and amniotic membrane (1). MSCs are one of the basic elements of the wound bed and would be introduced as an effective therapeutic method for wound repair (3) and studies have pronounced that MSCs are important trophic mediators to promote tissue regeneration $(1,3,4)$.

Adipose tissue has been known as a greatly encouraging, easy to access, cost-effective and plentiful source of MSCs as equal as the BM source (5). Adipose-derived mesenchymal stem cells (ASCs) are able to differentiate into several cell 
lineages such as osteogenic, chondrogenic, adipogenic, and neurogenic lineages (1). During wound healing, secreted cytokines by ASCs may activate fibroblast relocation and up-regulation of neovascularization in animal models $(5,6)$. These multipotent cells were determined to display significant potential for various applications in skin repair $(6,7)$.

Skin is a complex organ that applies essential capacities far beyond its role as a physical barrier (8). Due to high radiosensitivity of skin cellular components, exposure to radiation could lead to extreme damage to the skin barrier function, regeneration capability, and capillary integrity, because of modifications to the cellular communications between dermal fibroblasts, keratinocytes and immunocompetent cells $(9,10)$.

However, skin radiosensitivity has constrained the radiotherapy and radio-oncology process $(11,12)$. Several studies have discussed that almost all patients receiving radiation demonstrate various severity of skin reactions (9-12). Erythema, swelling, blisters, ulceration, necrosis and sclerosis are the manifestations of skin response to ionizing radiation depending on the radiation dose, quality and the depth of radiation penetration (9-12).

As recently radiotherapy has turned into a broadly used valuable alternative method of cancer treatment, different skin reactions may be seen (12). The damage to the skin may be significant during this process and its function notably impaired because of oxidative stress induced by radiation which has important effects on DNA and other macromolecules in the skin $(13,14)$. Therefore, radiationinduced skin injury is still a serious issue limiting the dose and duration of radiation use $(11,12)$.

On the other hand, clinical trials are raised in MSCs therapeutic function for accelerating thermal burn wound closure and for the treatment of serious radiation burns (15). The idea that stem cell injection could be applied for reducing normal tissue injury or helping its recovery after irradiation has been investigated in recent years $(15,16)$. However, further studies are required before embarking on general therapeutic recommendation. Accordingly, the present study investigated the effects of ASCs on radiationinduced skin damage in rat.

We present the following article in accordance with the ARRIVE reporting checklist (available at http://dx.doi. org/10.21037/sci-2019-045).

\section{Methods}

In this experimental case-control study, we examined two groups of rats $(\mathrm{N}=32)$ each containing 16 female rats (weighing 180-250 gr and 8 weeks of age), 16 rats as cases and 16 rats in the control group. Every 2 weeks a group of rats were sacrificed and pathological examinations were performed. This study is approved by the Research Ethics Committee of Shiraz University of Medical Sciences (reference number: IR.SUMS.REC.1394.S871), in compliance with Shiraz University of Medical Sciences guidelines for the care and use of animals.

\section{Isolation, purification and expansion of ASCs}

Adipose tissue was isolated from peri uterine fat tissue of the rats and transferred immediately to Stem Cell Laboratory of Shiraz Institute for Cancer Research (ICR), SUMS. These tissues were then chopped and fragmented into small pieces and were incubated in $37^{\circ} \mathrm{C}$ with collagenase type $\mathrm{I}$, in order to be digested completely and unified into a soup. Then the obtained soup was centrifuged, the processed pellet was brought on ficoll and the resulting cells were cultured in DMEM culture media (GIBCO, USA) supplemented with $10 \%$ fetal bovine serum (FBS) and penicillin/streptomycin (Biosurn, UK). In order to ensure the homogeneity of the cells in the sample, the ASCs were used after 3 passages.

\section{Local radiation}

The rats received a 30 Gy single dose to their buttocks skin at a dose rate of about $0.28 \mathrm{~Gy} / \mathrm{min}$ using the gamma radiation from a Cobalt- 60 external beam radiotherapy unit. A $0.5 \mathrm{~cm}$ perspex plate was placed adjacent to their skin to increase the skin dose to the stated value.

\section{ASCs transplantation}

Twenty-four hours after irradiation, $1 \times 10^{6}$ ASCs $/ 300 \mu \mathrm{L}$ PBS were transplanted locally in the case group using Myjector insulin syringe; PBS injected rats were used as the control group.

\section{Sample analysis}

The rats were examined and observed by macroscopic analysis, phenotypic score $[0,1,2,3]$ and histological assay (Abramov's histological scoring system) during 4 weeks of follow up, weekly. Skin samples were collected from irradiated areas of treated or untreated rats, fixed in $10 \%$ formalin and were analyzed. Histologic analysis was performed using hematoxylin and eosin (H\&E) staining. 


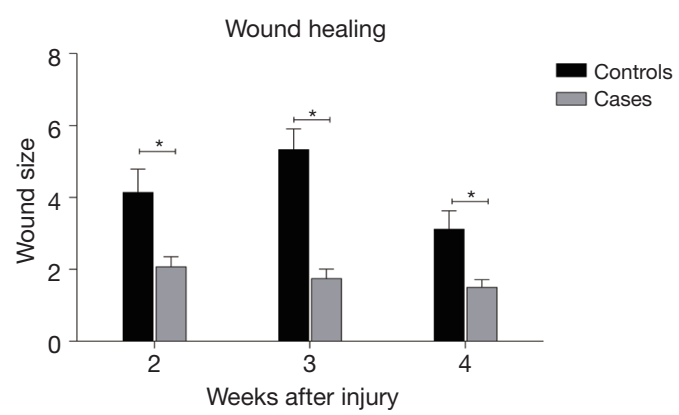

Figure 1 The process of wound healing in the case and control groups during the time. Data is shown as the mean $\pm \mathrm{SD}$. * demonstrates $\mathrm{P}<0.05$.

\section{Phenotypic score}

At first, the hairs of the legs were removed straight away after irradiation to facilitate the observations. A phenotypic score (LENT/SOMA scale) adapted to the model for severity of skin lesion evaluation $(0=$ normal, $1=$ dry desquamation, $2=$ moist desquamation and $3=$ ulceration) and was weekly checked for 8 weeks. The four selected area was examined under 400× magnifications. The Abramov's histological scoring system (modified Greenhalgh's scoring system) was performed for pathologic evaluation and scoring epithelization, angiogenesis, fibrosis, and collagen level; the number of macrophages under this system was determined. The collagen level was graded as follows: 0 (none), 1 (scant), 2 (moderate), and 3 (abundant). Epithelization was graded as either: 0 (none), 1 (partial), 2 (complete, but immature or thin) and 3 (complete and mature). Angiogenesis was graded as either 0 (none), 1 [up to 5 vessels per high power field (HPF)], 2 (6-10 vessels per HPF), and 3 (more than 10 vessels per HPF). Fibrosis was graded as 0 (none to minimal fibroblasts), 1 (few fibroblasts), 2 (more fibroblasts) and 3 (predominantly fibroblasts). The number of macrophages was scored as $1=0-25,2=26-50$, and $3=>51$.

\section{Wound assessment}

For evaluating the impact of stem cell on the skin damages during time, wound size, the onset of the lesion, injury severity (scale), the time of recovery signs begin (resorption) and the time of maximum size of lesion (peak) were measured and compared in both groups at the specified time.

\section{Statistical analysis}

Statistical Package for Social Science (SPSS) 20 was used for data analyses. Descriptive results were reported using mean, standard deviation, median, minimum and maximum values in tables or figures. In the analytical part Mann-Whitney $\mathrm{H}$ nonparametric test was used in order to compare a quantitative variable or an ordinal one between two groups. A $\mathrm{P}$ value $<0.05$ was considered significant in all statistical analyses.

\section{Results}

\section{Evaluation of wound size in the case and control groups}

There was a significant difference in wound size between cases and controls in the second, third and fourth weeks of evaluation $(\mathrm{P}<0.05)$. The wound size was $4.14 \pm 2.59$ and $2.07 \pm 1.16$ in the control and case groups, respectively, after 2 weeks $(\mathrm{P}=0.029)$. It was $5.33 \pm 2.29$ in the control group and $1.75 \pm 1.04$ in the case group after 3 weeks $(\mathrm{P}=0.004)$. After 4 weeks, the wound size was $3.11 \pm 2.09$ in the control group and $1.5 \pm 0.89$ in the case rats $(\mathrm{P}=0.036)$. Therefore, the wound healing process was faster in the case group Figure 1.

\section{The severity of skin lesion}

The results of Mann-Whitney test comparing the severity of skin lesion showed no significant difference between the case and control groups in none of the weeks evaluated $(\mathrm{P}>0.05)$. The onset of recovery signs also showed no statistically significant difference $(\mathrm{P}=0.97)$.

\section{Comparison of the pathologic factors between the case and the control groups}

The pathologic factors were compared between case and control groups. Considering the results in Table 1 and Figure 2, no significant difference was found in pathological factors between two groups $(\mathrm{P}>0.05)$.

Comparison of collagen showed that in 14 rats in the control group and all 16 rats in the case group [except 1 rat (grade 0) which collagen was not seen] the amount of collagen was high (grade 3).

Epithelization was complete in 14 rats in the control group and all of the evaluated cells were mature (grade 3). The epithelization was also complete in 16 rats in the case group except one rat which epithelization was not seen (grade 0), and the cells were all mature in the case group (grade 3).

Angiogenesis had not been occurred in any 14 rats in 
Table 1 Comparison of pathologic factors between case and control groups

\begin{tabular}{lccc}
\hline Group factor & Control group, median [min-max] & Case group, median [min-max] & $P$ value \\
\hline Collagen & $3[3-3]$ & $3[0-3]$ & 0.79 \\
Epithelialization & $3[3-3]$ & $3[0-3]$ & 0.79 \\
Angiogenesis & $0[0-0]$ & $0[0-3]$ & 0.154 \\
Fibrosis & $1[1-1]$ & $1[1-3]$ & 0.154 \\
Macrophages & $1[1-1]$ & $1[1-3]$ & 0.79 \\
\hline
\end{tabular}
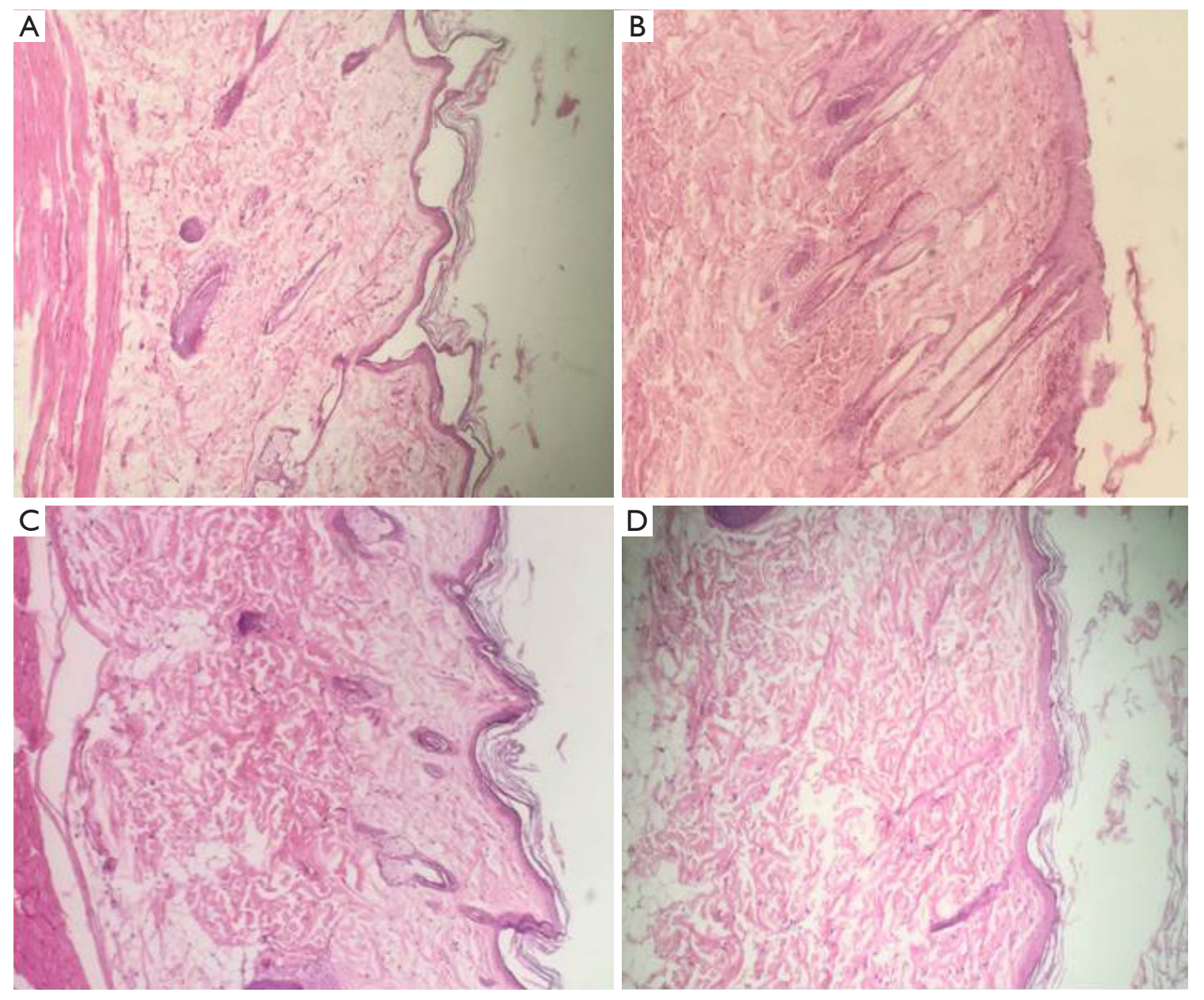

Figure 2 Comparison the pathologic factors between the case and the control groups. There was no significant difference in pathological factors between case and control groups 4 and 6 weeks post transplantation of ASCs and all images show complete reepithelialization and dermal fibrosis. (A) A sample of case group after 4 weeks; (B) a sample of control group after 4 weeks; (C) a sample of case group after 6 weeks; (D) a sample of control group after 6 weeks; hematoxylin and eosin (H\&E) staining, $\times 100$.

the control group (grade 0). There was no angiogenesis in 11 rats of the case group (grade 0), but in 4 rats there was 5 new vessels in each microscopic field (grade 1). And one case rat had more than 10 new vessels in each microscopic field (grade 3).

Fibroblasts were few in the control rats (grade 1), also 
11 rats in the case group had few fibroblast cells (grade 1). In 3 case rats more fibroblasts have been observed (grade 2 ), however, 2 case rats were presented with grade 3 (predominantly fibroblasts).

In the control group as well as the case group the number of macrophages was between 0-25 (grade 1) but just one case rat had 51 macrophages (grade 3).

\section{Discussion}

MSC therapy proposes an exciting possibility in the treatment of acute and chronic non healing wounds through various mechanisms including reepithelialization, differentiation, immunomodulation and production of distinct types of cytokines and growth factors. Secretion of proangiogenic factors by MSCs causes the recruitment of resident stem cells and endothelial cells and consequently neovascularization (17). It has been demonstrated that stem cells isolated from adipose tissue, BM and skin are capable of inducing regenerative mechanisms in skin and thus healing of wounds (3). Several studies have reviewed the effect of stem cell on wound healing especially in radiation-induced skin damage. François et al. showed the potential application of human MSCs to limit radiation-induced skin damages and suggested MSC as an alternative for the treatment of the early phase of the cutaneous radiation syndrome (18).

One of the most important stem cell sources for extracting MSCs is fat tissue with several advantageous including availability and easily isolation with high quantity as well as high quality in treatment (19). It is demonstrated that lipoaspirate transplantation is a low-invasive therapeutic approach resolving the problem of depressed skin, skin lesions, and wrinkles with decreased cost of skin care. Furthermore, it facilitates cell-mediated skin repair and regeneration (20). A smart communication between fibroblasts, mature adipocytes and immature adipocytes contributes to the proliferative phase of healing through repopulating of adipocytes in skin wound. Moreover, the localized loss of fat tissue is assigned with defects in wound healing; suggesting that adipocytes are essential for wound repair (21).

The present study assessed the ASCs' effect on radiationinduced skin damage in rat. Accordingly, evaluation of wound size during 8 weeks in case and control groups showed statistically significant difference between two groups at second, third and fourth weeks, so that wound size in the control group was notably higher than the case group in these 3 weeks. Similarly, Kim and coworkers reported the positive effects of ASCs on wound-healing via shortening reepithelialization time and reducing wound size in diabetic nude mice (22). BM-MSCs also showed positive effects for the healing of diabetic ulcers as significant decrease in wound size was observed after topical use of MSCs (23).

The onset of recovery signs presentation in radiationinduced skin damage was evaluated, but we did not find significant difference between the control and case groups. Likewise, no difference was observed between case and control groups in the amount of collagen, epithelization, angiogenesis and the number of fibroblasts as well as macrophages. Considering these results, we can conclude that ASCs may play a significant role in decreasing the wound size, however, the effectiveness of these cells was not approved for skin lesion severity, pathological factors or onset of recovery signs. Based on our results, it can be hypothesized that ASCs' ability for differentiation to epithelial cells is probably lower than BM-MSCs and using ASCs beside growth factors or PRP will probably demonstrate more impact. Accordingly, in a study by Hadad et al. who developed a delayed fullthickness wound-healing model, it has been shown that the healing rates of perfusion-depleted tissues enhances using ASCs together with PRP, but neither ASCs nor PRP alone were effective (24). Also, BM-MSCs and human amniotic epithelial cells (HAECs) are assigned as effective cells in the healing of irradiated wounds. Based on this study, BM-MSCs showed a great effect on the quality of the dermis, while HAECs showed advantage for the epithelium and its appendages (25). Local injection of BM-MSCs into an incisional full-thickness wound induced angiogenesis, reepithelialization, and granulation and thus considerably accelerate wound healing. These cells showed direct contribution to cutaneous regeneration via keratin expression and formation of glandular structures. Interestingly, the condition media from BM-MSC contributed to endothelial cell tube formation (26). Further studies are provided showing the advantage of using BM-MSCs in the treatment of acute surgical wounds and chronic non-healing diabetic ulcers $(27,28)$. Anyway, limitations to this study include short follow-up periods, small sample size and the use of animal model.

Altogether, despite the effect of ASCs on wound size, stem cells extracted from other sources like BM appear to be more capable of differentiating into epithelial cells and thus more effective in wound healing. However, combination of ASCs and growth factors may show satisfactory results for cutaneous radiation syndrome therapy. 


\section{Acknowledgments}

The authors would like to thank the employees of Laboratory Animal Department of SUMS for caring the animals studied. This research was done as a requirement for the special Ear, Nose, and Throat thesis defended by Dr. SS.

Funding: This work was financially supported by Shiraz University of Medical Sciences, Shiraz, Iran (Grant No. 93-01-01-8591) and Shiraz Institute for Cancer Research (ICR-100-504).

\section{Footnote}

Reporting Checklist: The authors have completed the ARRIVE reporting checklist. Available at http://dx.doi. org/10.21037/sci-2019-045

Conflicts of Interest: All authors have completed the ICMJE uniform disclosure form (available at http://dx.doi. org/10.21037/sci-2019-045). The authors have no conflicts of interest to declare.

Ethical Statement: The authors are accountable for all aspects of the work in ensuring that questions related to the accuracy or integrity of any part of the work are appropriately investigated and resolved. This study is approved by the Research Ethics Committee of Shiraz University of Medical Sciences (reference number: IR.SUMS.REC.1394.S871), in compliance with Shiraz University of Medical Sciences guidelines for the care and use of animals.

Open Access Statement: This is an Open Access article distributed in accordance with the Creative Commons Attribution-NonCommercial-NoDerivs 4.0 International License (CC BY-NC-ND 4.0), which permits the noncommercial replication and distribution of the article with the strict proviso that no changes or edits are made and the original work is properly cited (including links to both the formal publication through the relevant DOI and the license). See: https://creativecommons.org/licenses/by-nc-nd/4.0/.

\section{References}

1. Deans RJ, Moseley AB. Mesenchymal stem cells: biology and potential clinical uses. Exp Hematol 2000;28:875-84.

2. Friedenstein AJ, Chailakhjan RK, Lalykina KS. The development of fibroblast colonies in monolayer cultures of guinea-pig bone marrow and spleen cells. Cell Tissue Kinet 1970;3:393-403.

3. Marfia G, Navone SE, Di Vito C, et al. Mesenchymal stem cells: potential for therapy and treatment of chronic nonhealing skin wounds. Organogenesis 2015;11:183-206.

4. Fu X, Li H. Mesenchymal stem cells and skin wound repair and regeneration: possibilities and questions. Cell Tissue Res 2009;335:317-21.

5. Gaur M, Dobke M, Lunyak VV. Mesenchymal stem cells from adipose tissue in clinical applications for dermatological indications and skin aging. Int J Mol Sci 2017;18:208.

6. Nakagami H, Morishita R, Maeda K, et al. Adipose tissuederived stromal cells as a novel option for regenerative cell therapy. J Atheroscler Thromb 2006;13:77-81.

7. Schäffler A, Büchler C. Concise review: adipose tissuederived stromal cells--basic and clinical implications for novel cell-based therapies. Stem Cells 2007;25:818-27.

8. Hopewell JW. The skin: its structure and response to ionizing radiation. Int J Radiat Biol 1990;57:751-73.

9. Peter RU, Gottlöber P. Management of cutaneous radiation injuries: diagnostic and therapeutic principles of the cutaneous radiation syndrome. Mil Med 2002;167:110-2.

10. Lima CM, Lima AR, Degenhardt ÄL, et al. Reconstructive dosimetry for cutaneous radiation syndrome. Braz J Med Biol Res 2015;48:895-901.

11. Zhu W, Jia L, Chen G, et al. Epigallocatechin-3-gallate ameliorates radiation-induced acute skin damage in breast cancer patients undergoing adjuvant radiotherapy. Oncotarget 2016;7:48607-13.

12. Lindholm CE, Kjellén E, Nilsson P, et al. Prognostic factors for tumour response and skin damage to combined radiotherapy and hyperthermia in superficial recurrent breast carcinomas. Int J Hyperthermia 1995;11:337-55.

13. Svobodová A, Vostálová J. Solar radiation induced skin damage: review of protective and preventive options. Int J Radiat Biol 2010;86:999-1030.

14. Swindells K, Rhodes LE. Influence of oral antioxidants on ultraviolet radiation-induced skin damage in humans. Photodermatol Photoimmunol Photomed 2004;20:297-304.

15. Akita S, Akino K, Hirano A, et al. Mesenchymal stem cell therapy for cutaneous radiation syndrome. Health Phys 2010;98:858-62.

16. Riccobono D, Agay D, Scherthan H, et al. Application of adipocyte-derived stem cells in treatment of cutaneous 
radiation syndrome. Health Phys 2012;103:120-6.

17. Prodinger CM, Reichelt J, Bauer JW, et al. Current and future perspectives of stem cell therapy in dermatology. Ann Dermatol 2017;29:667-87.

18. François S, Mouiseddine $M$, Mathieu N, et al. Human mesenchymal stem cells favour healing of the cutaneous radiation syndrome in a xenogenic transplant model. Ann Hematol 2007;86:1-8.

19. Hassan WU, Greiser U, Wang W. Role of adiposederived stem cells in wound healing. Wound Repair Regen 2014;22:313-25.

20. Salahat MA, Al Hadid L. Autologous adipose stem cells use for skin regeneration and treatment in humans. Journal of Biology, Agriculture and Healthcare 2013;3:135-42.

21. Schmidt BA, Horsley V. Intradermal adipocytes mediate fibroblast recruitment during skin wound healing. Development 2013;140:1517-27.

22. Kim EK, Li G, Lee TJ, et al. The effect of human adipose-derived stem cells on healing of ischemic wounds in a diabetic nude mouse model. Plast Reconstr Surg 2011;128:387-94.

23. Isakson M, de Blacam C, Whelan D, et al. Mesenchymal

doi: $10.21037 /$ sci-2019-045

Cite this article as: Khademi B, Safari S, Mosleh-Shirazi MA, Mokhtari M, Chenari N, Razmkhah M. Therapeutic effect of adipose-derived mesenchymal stem cells (ASCs) on radiationinduced skin damage in rats. Stem Cell Investig 2020;7:12. stem cells and cutaneous wound healing: current evidence and future potential. Stem Cells Int 2015;2015:831095.

24. Hadad I, Johnstone BH, Brabham JG, et al. Development of a porcine delayed wound-healing model and its use in testing a novel cell-based therapy. Int J Radiat Oncol Biol Phys 2010;78:888-96.

25. Mehanni SS, Ibrahim NF, Hassan AR, et al. New approach of bone marrow-derived mesenchymal stem cells and human amniotic epithelial cells applications in accelerating wound healing of irradiated albino rats. Int J Stem Cells 2013;6:45-54.

26. Wu Y, Chen L, Scott PG, et al. Mesenchymal stem cells enhance wound healing through differentiation and angiogenesis. Stem Cells 2007;25:2648-59.

27. Falanga V, Iwamoto S, Chartier M, et al. Autologous bone marrow-derived cultured mesenchymal stem cells delivered in a fibrin spray accelerate healing in murine and human cutaneous wounds. Tissue Eng 2007;13:1299-312.

28. Dash NR, Dash SN, Routray P, et al. Targeting nonhealing ulcers of lower extremity in human through autologous bone marrow-derived mesenchymal stem cells. Rejuvenation Res 2009;12:359-66. 